\title{
Review Article \\ Vaccination of Adult Patients with Systemic Lupus Erythematosus in Portugal
}

\author{
Maria Francisca Moraes-Fontes, ${ }^{1,2}$ Ana Margarida Antunes, \\ Heidi Gruner, ${ }^{1,2}$ and Nuno Riso ${ }^{1,2}$ \\ ${ }^{1}$ Unidade de Doenças Auto-Imunes, Serviço Medicina 7.2, Hospital Curry Cabral, Centro Hospitalar Lisboa Central, \\ 1069-166 Lisbon, Portugal \\ ${ }^{2}$ Núcleo de Estudos de Doenças Autoimunes (NEDAI) da Sociedade Portuguesa de Medicina Interna, Portugal
}

Correspondence should be addressed to Maria Francisca Moraes-Fontes; mffontes@igc.gulbenkian.pt

Received 16 November 2015; Accepted 16 February 2016

Academic Editor: Bruce M. Rothschild

Copyright (c) 2016 Maria Francisca Moraes-Fontes et al. This is an open access article distributed under the Creative Commons Attribution License, which permits unrestricted use, distribution, and reproduction in any medium, provided the original work is properly cited.

In the wake of the Portuguese vaccination program 50th anniversary it seems appropriate to review vaccination in patients with systemic lupus erythematosus. Controversial issues as regards the association between autoimmune diseases, infections, and vaccines are discussed as well as vaccine safety and efficacy issues as regards chronic immunosuppressant (IS) drug therapy. After a brief overview of national policies, specific recommendations are made as regards vaccination for adult patients with SLE with a particular focus on current IS therapy and unmet needs.

\section{Introduction}

Vaccines induce long lasting protective immunity against microbial pathogens, prevent clinically relevant infections, and constitute one of the most important medical interventions ever. Nevertheless, vaccination plans differ across nations in several respects: they are not always free of charge nor compulsory, not all schools require a vaccination certificate, there are different brands and combinations, boosters are given at different times and in some areas of the world, and due to political interference, vaccination is actually banned [1]. This review describes the Portuguese National Vaccination Plan and provides the clinician with an easy guide to the expected vaccination status according to a patient's age. Vaccine side-effects with a focus on autoimmunity and specific indications for vaccination in SLE patients are discussed together with the expected impact of immunosuppression upon vaccine efficacy and safety.

\section{The Portuguese National Vaccination Plan}

The National Vaccination Plan (NVP) in Portugal commemorates 50 years in 2015. It was officially started in 1965 and is free of charge for all, including migrants. It has also been continuously updated by governmental decree up until June 2015, when pneumococcal conjugate vaccine to newborns was added [2]. Of note, there are also specific recommendations for unvaccinated adult immigrants [3]. The state also actively implements rubella vaccination to every nonpregnant woman aged over 18 whose vaccination status is unknown, even in the postpartum period. Only diphtheria and tetanus are compulsory in Portugal, with revaccination being recommended every 10 years. Nevertheless, vaccination denial is rarely reported [4], refusal is generally met with disapproval, and vaccination procedures are highly regulated. In addition, should patients lose their vaccination record, it may be recovered through a registration database used in every health centre since the year 2000 [5]. All nationally administered vaccines are imported.

Most of the information on current rates of infection is available from websites issued by the Portuguese Directorate General for Health. Diphtheria, poliomyelitis, rubella, and measles have been eradicated in Portugal [6] but there are still sporadic reports of rural tetanus in unvaccinated individuals [7], pertussis in the first year of life [8], and mumps [9]. Furthermore, there is still a notoriously high estimated 
TABLE 1: (a) Vaccination, (b) vaccination as part of NVP, (c) ages at which vaccination is administered, and (d) age above which patients are not expected to have been vaccinated in Portugal up to December 2015; m: months; y: years.

(a) Infection

(b) Vaccination as part of NVP

(c) Age of administration ( $\mathrm{m}$ or $\mathrm{y}$ ) (d) Age (y) above which patients are not expected to be vaccinated

\begin{tabular}{lccc}
\hline Pertussis & $1963-1965$ & $2 \mathrm{~m}$ & 52 \\
Poliomyelitis & 1965 & $2 \mathrm{~m}$ & 50 \\
$\begin{array}{l}\text { Mumps and } \\
\text { rubella }\end{array}$ & 1974 & $12 \mathrm{~m}$ & 41 \\
Measles & 1987 & $12 \mathrm{~m}$ & 44 \\
$\begin{array}{l}\text { Hepatitis B } \\
\text { Haemophilus } \\
\text { influenzae B }\end{array}$ & $2000(0+13$ years old at onset of campaign $)$ & $2 \mathrm{~m}$ & 28 \\
$\begin{array}{l}\text { Human papilloma } \\
\text { virus }\end{array}$ & 2000 & $12 \mathrm{y}$ & 28 \\
Meningococcal C & $2008(13 \mathrm{y}), 2009(17 \mathrm{y})$ & $12 \mathrm{~m}$ & $20-23$ \\
\hline
\end{tabular}

incidence of hepatitis B (1.98/100000) [10] and tuberculosis (21.6/100000) [11], the latter remaining one of the highest in Western Europe. Accordingly, the latest NVP has been very recently updated [12].

In Portugal, depending on year of vaccine introduction and patient age, some patients are not expected to have been vaccinated (Table 1). For BCG, it is difficult to provide such an age estimate because there was a revaccination policy for Mantoux anergic individuals (the latter was stopped in 2005). Nevertheless, BCG vaccination at birth was implemented in 1963 and the typical vaccination scar may be recognized. Of note, hepatitis A vaccination is not part of the NVP but a recent Portuguese study showed that individuals under 25 years of age are at particular risk of infection [13].

\section{The Etiological Role for Infections and Vaccination in Autoimmune Diseases}

Vaccines are not without risk and the degree of vaccinerelated risk should always be compared to that associated with the corresponding natural infection. The issue of an etiological role for infections and vaccination in autoimmune diseases (AID) remains controversial. Autoimmunity is generally assumed to result from complex interaction between genetic traits and environmental factors and therefore it may be argued that until the pathogenesis of AID is fully understood, the real risk of an infection or vaccination cannot be clearly defined. Furthermore, autoimmune responses are not necessarily accompanied by any clinical manifestation and may precede disease expression and their frequency is inversely related to a global decline in infections [14]. In addition, epidemiological studies are difficult, as humans accumulate many infections by the time early adulthood is reached and while infections are common, AID are much rarer diseases. Insomuch as several infections have been associated with the onset of AID, both experimentally and in humans [15], distinguishing temporal association from causality remains a daunting task, exemplified by
TABLE 2: Reported associations between vaccination and autoimmune diseases.

\begin{tabular}{lc}
\hline Vaccine/adjuvant & Disease \\
\hline Measles, mumps, and rubella & $\begin{array}{c}\text { Immune thrombocytopenic } \\
\text { purpura [19] }\end{array}$ \\
Hepatitis B vaccine 1991-1997 & Multiple sclerosis [65], one \\
study \\
H1N1 influenza vaccine in 2009 & Narcolepsy [66] \\
Hepatitis B vaccination & Undifferentiated connective \\
Human papilloma virus & tissue disease [67, 68] \\
\hline
\end{tabular}

TABLE 3: Lack of associations between vaccination and autoimmune diseases.

\begin{tabular}{lc}
\hline Vaccine/adjuvant & Disease \\
\hline $\begin{array}{l}\text { Hepatitis B vaccine 1991-1997 } \\
\text { Haemophilus influenzae type B } \\
\begin{array}{l}\text { Measles, mumps, and } \\
\text { rubella/thimerosal } \\
\text { Tetanus, influenza, and hepatitis B }\end{array}\end{array}$ & $\begin{array}{c}\text { Multiple sclerosis [70], 5 } \\
\text { studies }\end{array}$ \\
\hline
\end{tabular}

the link between narcolepsy and the H1N1 strain of influenza epidemic described in Northern Europe [16], but not in the USA [17]. Vaccine-related AID has been convincingly demonstrated, an example of which is the Guillain-Barré syndrome specifically associated with the $1976-77$ vaccination campaign using the A/New Jersey/8/76 swine-flu vaccine [18]. Other rarely described associations have been described (Table 2).

Measles infection itself is associated with autoimmune thrombocytopenia [19] and prior suspicions of risks for multiple sclerosis, type 1 diabetes, autism, and rheumatoid arthritis have been subsequently disproven (Table 3). Adjuvants licensed for human use are coadministered in all except live vaccines, to enhance immunogenicity [20], and 
mostly consist of aluminium phosphate/hydroxide, oil in water emulsions (squalene), and liposomes [21]. Aluminium in vaccines and diet has been convincingly shown to lack adverse effects in infants in the first year of life [22] but aluminium itself, squalene, and all other currently used adjuvants have been associated with autoimmunity in a recent collection of reports grouping gulf war syndrome, siliconosis, macrophagic myofasciitis, and postvaccination syndrome collectively known as ASIA, autoimmune/inflammatory syndrome. In ASIA, the causative role of adjuvants is based on experimental models for which several immune-mediated mechanisms have been proposed [23]. An attempt to establish causality has to be done on a case-by-case basis, through the demonstration of a consistent nonrandom temporal association between AID and vaccination. So far, there are no minimum specific criteria established for AID induced by vaccination diagnosis and studies are awaited to verify this hypothesis. Whether SLE drug therapies such as hydroxychloroquine are protective in this respect remains speculative.

\section{Vaccination Status in SLE Patients according to the Portuguese National Vaccination Program}

According to EULAR recommendations, vaccination status should be assessed in the initial workup of patients with autoimmune conditions [24]. It is expected to vary depending on the patient's age and corresponding NVP. In clinical practice one should bear in mind that SLE mostly affects women and that the mean age of diagnosis is 31 years [25]. With reference to Table 1 , when the schedule of the Portuguese NVP is taken into consideration, the only vaccination that remains a real concern in Portuguese patients is that against human papilloma virus (HPV). In the general population, epidemiological studies document a significant risk of infection until the age of 50 , such that sexually active women are thought to potentially benefit from vaccination $[26,27]$. This benefit is expected to be even higher in patients with SLE due to higher rates of persistent HPV infection, high-grade cervical dysplasia, and cervical cancer [28-31]. Pertussis, Haemophilus influenzae type B, and Meningococcal $\mathrm{C}$ would generally only be expected to occur in infants but the latter two are of particular concern in splenectomised patients. As already mentioned, poliomyelitis, measles, and rubella have been eradicated in Portugal. In the light of the recent influx of patients into Europe, special attention should nevertheless be paid to the following vaccinations: Haemophilus influenzae type B, Neisseria meningitidis, rubella (for women of childbearing age), tetanus, and hepatitis A and B. It must be emphasized that vaccination should preferably be performed in patients with stable disease [24] and as a general rule, whenever possible, titres should be checked, infection excluded, and vaccination administered accordingly.
TABle 4: Vaccine recommendations in adult Portuguese patients with systemic lupus erythematosus.

\begin{tabular}{lc}
\hline Diphtheria and tetanus & Every 10 years \\
\hline Human papilloma virus & Sexually active females \\
\hline Seasonal influenza & Yearly \\
\hline Pneumococcal polysaccharide & Repeat once after 5 years [74] \\
\hline Pneumococcal conjugate & Single administration $[75]$ \\
\hline
\end{tabular}

\section{Recommended Vaccines in SLE Patients}

There are no clinically applicable scores that allow for the prediction of individual risk of infections in patients with SLE, particularly in those patients on immunosuppressive (IS) drugs which generally increase the risk of infection. Infection is, at present, one of the leading causes of death in SLE patients [25, 32, 33]. However, most bacterial, viral, fungal, and other infections that occur in SLE patients, namely, Escherichia coli, Staphylococcus aureus [34], cytomegalovirus, parvovirus B19, herpes simplex and Epstein-Barr virus [35], Cryptococcus neoformans, Candida albicans [36], and Pneumocystis [37], are not preventable by vaccines, as these have as yet to be developed and childhood/adolescent immunization against these pathogens will be highly desirable once these become available. In stark contrast, there are effective vaccines against invasive Streptococcus pneumoniae infections, to which SLE patients are particularly prone [38] and which are therefore recommended. Other infections of epidemic/pandemic nature such as influenza cause significant morbidity and mortality in the general population and yearly influenza vaccination is also recommended in patients with SLE $[39,40]$. These recommendations are put forward by expert panels and take into account the frequent use of IS medication despite a lack of evidence that SLE patients are more frequently or severely affected by influenza or present additional risks of bacterial superinfection due to corticosteroid use [41]. In Portugal, pneumococcal polysaccharide vaccine and annual influenza vaccines are optional and partially state subsidized while the pneumococcal conjugate vaccine is not state supported for adults. Optimally, both pneumococcal vaccines should be administered following specific administration timings recently reviewed in detail [42]. Vaccinations commonly used in adult Portuguese SLE patients are presented in Table 4.

\section{The Effect of Immunosuppressive Drugs on Vaccine Efficacy and Safety}

Drugs used in chronic immunosuppression of SLE patients have a multiplicity of targets, may deplete cellular subsets, target intracellular signals involved in B and T-cell activation, and inhibit macrophage function. Few studies have systematically addressed the possibility that the most commonly chronically used IS drugs affect the rates of seroconversion after influenza and pneumococcal vaccination and even fewer have studied the long term protective effect of vaccination. 
SLE patients may have a blunted immune response to influenza vaccination [43]. Exceptionally, a single study evaluated the effect of hydroxychloroquine and a stable dose of prednisolone and azathioprine on the rate of seroconversion one month following influenza vaccination and found that only azathioprine was associated with lower influenza antibodies [44]. It is currently unknown whether SLE patients maintain their titres following vaccination allowing for sufficient protection during the whole influenza season. Although the effect of mycophenolate mofetil (MMF) and rituximab (RTX) has not specifically been assessed in lupus patients, MMF diminishes influenza seroconversion in transplant recipients [45] and RTX has a similar effect in rheumatoid arthritis (RA) patients $[46,47]$. In the latter patients, methotrexate does not significantly diminish humoral responses to vaccination $[48,49]$.

SLE patients may display nonprotective responses to the pneumococcal vaccine but no correlation has been made with the type and dose of IS [50]. In SLE patients, hepatitis $\mathrm{B}$ vaccine response may be impaired and serological responses should be assessed after vaccination [51]. RTX reduces responses to pneumococcal vaccine but this has only been studied in RA $[47,52]$. Ideally, patients should be vaccinated before undergoing $B$ cell depletion therapy. Belimumab does not seem to reduce vaccine antibodies to influenza, pneumococcal, and tetanus vaccines [53]. As a general rule, inactivated vaccines should be administered at least 14 days before initiation of immunosuppressive therapy to optimize immunogenicity.

It should be noted that even though childhood chickenpox can be associated with severe complications [54] and the vaccine is safe and effective $[54,55]$, chickenpox immunization is only offered to children in Australia, Canada, Germany, Korea, Qatar, Saudi Arabia, Taiwan, Uruguay, Sicily, and Madrid [56]. The vaccine is live, may cause disseminated infection in immunocompromised patients [57], and effectively remains excluded from most vaccination programs as there are still widespread worries that it may increase the risk of chickenpox and shingles in older people. On the other hand, herpes zoster is still the most common viral infection in SLE patients treated with cyclophosphamide and mycophenolate mofetil [58]. There is a zoster vaccine which is 50 to $70 \%$ effective. It has been licensed since 2006 for immunization of immunocompetent individuals over age 60 years with no history of recent zoster $[59,60]$ and has also been shown to be effective between 50 and 59 years of age [61]. It cannot however be routinely recommended in SLE patients because it is a live vaccine which may pose a danger of generalized and even fatal infections in IS patients. It is not recommended in patients that test negative for varicella-specific antibodies, indicating absence of previous exposure. According to EULAR guidance, zoster vaccination is contraindicated when steroids are used for $\geq 14$ days, at a dose of $20 \mathrm{mg}$ of prednisone equivalent or higher and with the use of azathioprine $\geq 3.0 \mathrm{mg} / \mathrm{kg} /$ day or methotrexate at $\geq 0.4 \mathrm{mg} / \mathrm{kg} /$ week [24]. Results of a recent trial are awaited, intended to test safety, tolerability, and immunogenicity of the zoster vaccine in patients receiving chronic/maintenance corticosteroids [62]. No information on MMF or belimumab is available as regards zoster vaccination safety. As a general rule it seems prudent to check immune reconstitution in patients that have been subjected to IS therapy in high dosage or for long periods of time before zoster vaccination is prescribed. Live vaccines are contraindicated in patients undergoing biological therapy [42].

Detailed information about traveler needs and emerging infections [21] is beyond the scope of this paper. As already mentioned, live vaccines such as for yellow fever may cause an infection in significantly IS individuals. On the other hand, pathogen born yellow fever infection has a high mortality. Personalized decisions should therefore be made as regards vaccine administration, therapy delays, or drug holidays. Of note, yellow fever vaccine is safe in HIV positive individuals with adequate $\mathrm{CD}^{+}$T-cell counts [63] and in transplant recipients [64].

\section{Conclusion}

In conclusion, the overall balance is in favour of vaccination in patients with SLE. Infection/vaccine induced AID remains a theoretical possibility and there are documented effects of IS drugs on vaccine efficacy and safety. Vaccination records according to NVP should be routinely performed in the initial workup of SLE patients and additional vaccinations prescribed as required, bearing in mind that vaccination should be preferably performed when the disease is in remission. Seasonal influenza, pneumococcal, and HPV vaccination are actively encouraged. Whenever possible, protective titres should be checked for rubella and hepatitis A and B, preventing unnecessary vaccination. Live vaccination must be individualized and may be performed in non- or mildly immunosuppressed patients but data is awaited regarding their safety in patients that require higher dosages of IS. As a whole, vaccination is safe and should be supported as part of standard of care in patients with SLE in whom infections are a significant cause of morbidity and mortality. It is also hoped that new vaccines will greatly contribute to progress in improving healthcare and that old vaccines will be optimized to provide extended protection.

\section{Competing Interests}

The authors declare that they have no competing interests.

\section{References}

[1] "Global polio eradication: not there yet," The Lancet, vol. 381, no. 9860, p. 1, 2013.

[2] http://www.portaldasaude.pt/NR/rdonlyres/A3829F73-E5EF4AE8-B10B-A9A8B90392C4/0/Despacho5786_2015.pdf.

[3] http://www.oi.acidi.gov.pt/docs/rm/Brochuras/saude.pdf.

[4] http://www.ordemenfermeiros.pt/documentos/Documents/ Parecer\%2011_MCEESIP.pdf.

[5] http://www.acss.min-saude.pt/Portals/0/VACINA\%C3\%87\% C3\%83O.pdf.

[6] http://www.spp.pt/UserFiles/file/Noticias/NotaInformativaVacina .pdf. 
[7] L. Castro, G. Gonçalves, and J. Catarino, "Reported cases of tetanus in the North of Portugal (1993-2002): missed opportunities for vaccination," Acta Medica Portuguesa, vol. 17, no. 3, pp. 225-230, 2004.

[8] http://www.insa.pt/sites/INSA/Portugues/PublicacoesRepositorio/ Documents/observa\%C3\%A7\%C3\%B5es\%20N\%C2\%BA\%20 Especial\%201\%202013_artigol.pdf.

[9] http://www.insa.pt/sites/INSA/Portugues/PublicacoesRepositorio/ Documents/observa\%C3\%A7\%C3\%B5es\%20N\%C2\%BA\%20 Especial\%201\%202013_artigo3.pdf.

[10] C. Koch and F. Araújo, "Evolution of residual risk for HIV, HCV and HBV, from 1999 to 2010, in blood donations of the Centro Hospitalar S. Joao, EPE, Porto, Portugal," Acta Medica Portuguesa, vol. 26, no. 4, pp. 371-376, 2013.

[11] C. Areias, T. Briz, and C. Nunes, "Pulmonary tuberculosis space-time clustering and spatial variation in temporal trends in Portugal, 2000-2010: an updated analysis," Epidemiology and Infection, vol. 143, no. 15, pp. 3211-3219, 2015.

[12] http://www.portaldasaude.pt/portal/conteudos/informacoes+ uteis/vacinacao/vacinas.htm.

[13] S. Pereira, I. Linhares, A. F. Neves, and A. Almeida, "Hepatitis a immunity in the district of Aveiro (Portugal): an eleven-year surveillance study (2002-2012)," Viruses, vol. 6, no. 3, pp. 13361345, 2014.

[14] M. R. Arbuckle, M. T. McClain, M. V. Rubertone et al., "Development of autoantibodies before the clinical onset of systemic lupus erythematosus," The New England Journal of Medicine, vol. 349, no. 16, pp. 1526-1533, 2003.

[15] D. C. Wraith, M. Goldman, and P.-H. Lambert, "Vaccination and autoimmune disease: what is the evidence?" The Lancet, vol. 362, no. 9396, pp. 1659-1666, 2003.

[16] L. Wijnans, C. Lecomte, C. de Vries et al., "The incidence of narcolepsy in Europe: before, during, and after the influenza A(H1N1)pdm09 pandemic and vaccination campaigns," Vaccine, vol. 31, no. 8, pp. 1246-1254, 2013.

[17] J. Duffy, E. Weintraub, C. Vellozzi, and F. Destefano, "Narcolepsy and influenza A(H1N1) pandemic 2009 vaccination in the United States," Neurology, vol. 83, no. 20, pp. 1823-1830, 2014.

[18] L. B. Schonberger, D. J. Bregman, J. Z. Sullivan-Bolyai et al., "Guillain-Barre syndrome following vaccination in the National Influenza Immunization Program, United States, 1976-1977," American Journal of Epidemiology, vol. 110, no. 2, pp. 105-123, 1979.

[19] V. Demicheli, A. Rivetti, M. G. Debalini, and C. Di Pietrantonj, "Vaccines for measles, mumps and rubella in children," Cochrane Database of Systematic Reviews, vol. 2, Article ID CD004407, 2012.

[20] B. N. Lambrecht and D. Y. M. Leung, "Initiation and maintenance of allergic inflammation: team work at the interface of innate and adaptive immunity," Current Opinion in Immunology, vol. 23, no. 6, pp. 769-771, 2011.

[21] R. Rappuoli, C. W. Mandl, S. Black, and E. De Gregorio, "Vaccines for the twenty-first century society," Nature Reviews Immunology, vol. 11, no. 12, pp. 865-872, 2011.

[22] R. J. Mitkus, D. B. King, M. A. Hess, R. A. Forshee, and M. O. Walderhaug, "Updated aluminum pharmacokinetics following infant exposures through diet and vaccination," Vaccine, vol. 29, no. 51, pp. 9538-9543, 2011.

[23] Y. Shoenfeld and N. Agmon-Levin, “'ASIA'-autoimmune/ inflammatory syndrome induced by adjuvants," Journal of Autoimmunity, vol. 36, no. 1, pp. 4-8, 2011.
[24] S. van Assen, N. Agmon-Levin, O. Elkayam et al., "EULAR recommendations for vaccination in adult patients with autoimmune inflammatory rheumatic diseases," Annals of the Rheumatic Diseases, vol. 70, no. 3, pp. 414-422, 2011.

[25] R. Cervera, M. A. Khamashta, and G. R. V. Hughes, "The Eurolupus project: epidemiology of systemic lupus erythematosus in Europe," Lupus, vol. 18, no. 10, pp. 869-874, 2009.

[26] F. X. Bosch, A. N. Burchell, M. Schiffman et al., "Epidemiology and natural history of human papillomavirus infections and type-specific implications in cervical neoplasia," Vaccine, vol. 26, supplement 10, pp. K1-K16, 2008.

[27] M. Schiffman, P. E. Castle, J. Jeronimo, A. C. Rodriguez, and S. Wacholder, "Human papillomavirus and cervical cancer," The Lancet, vol. 370, no. 9590, pp. 890-907, 2007.

[28] E. M. Klumb, A. C. Pinto, G. R. Jesus et al., "Are women with lupus at higher risk of HPV infection?" Lupus, vol. 19, no. 13, pp. 1485-1491, 2010.

[29] L.-S. Tam, P. K. S. Chan, S. C. Ho et al., "Natural history of cervical papilloma virus infection in systemic lupus erythematosusa prospective cohort study," Journal of Rheumatology, vol. 37, no. 2, pp. 330-340, 2010.

[30] W. Rojo-Contreras, E. M. Olivas-Flores, J. I. Gamez-Nava et al., "Cervical human papillomavirus infection in Mexican women with systemic lupus erythematosus or rheumatoid arthritis," Lupus, vol. 21, no. 4, pp. 365-372, 2012.

[31] S. C. Kim, R. J. Glynn, E. Giovannucci et al., "Risk of highgrade cervical dysplasia and cervical cancer in women with systemic inflammatory diseases: a population-based cohort study," Annals of the Rheumatic Diseases, vol. 74, no. 7, pp. 13601367, 2015.

[32] J. F. Merola, B. Bermas, B. Lu et al., "Clinical manifestations and survival among adults with (SLE) according to age at diagnosis," Lupus, vol. 23, no. 8, pp. 778-784, 2014.

[33] Y. Fei, X. Shi, F. Gan et al., "Death causes and pathogens analysis of systemic lupus erythematosus during the past 26 years," Clinical Rheumatology, vol. 33, no. 1, pp. 57-63, 2014.

[34] X. Bosch, A. Guilabert, L. Pallarés et al., "Infections in systemic lupus erythematosus: a prospective and controlled study of 110 patients," Lupus, vol. 15, no. 9, pp. 584-589, 2006.

[35] M. Ramos-Casals, M. J. Cuadrado, P. Alba et al., "Acute viral infections in patients with systemic lupus erythematosus: description of 23 cases and review of the literature," Medicine, vol. 87, no. 6 , pp. 311-318, 2008.

[36] H. S. Chen, W. P. Tsai, H. S. Leu, H. H. Ho, and L.-B. Liou, "Invasive fungal infection in systemic lupus erythematosus: an analysis of 15 cases and a literature review," Rheumatology, vol. 46, no. 3, pp. 539-544, 2007.

[37] K. Migita, T. Arai, N. Ishizuka et al., "Rates of serious intracellular infections in autoimmune disease patients receiving initial glucocorticoid therapy," PLoS ONE, vol. 8, no. 11, Article ID e78699, 2013.

[38] R. K. M. A. C. Luijten, B. V. J. Cuppen, J. W. J. Bijlsma, and R. H. W. M. Derksen, "Serious infections in systemic lupus erythematosus with a focus on pneumococcal infections," Lupus, vol. 23, no. 14, pp. 1512-1516, 2014.

[39] J. Yazdany, P. Panopalis, J. Z. Gillis et al., "A quality indicator set for systemic lupus erythematosus," Arthritis Care and Research, vol. 61, no. 3, pp. 370-377, 2009.

[40] M. Mosca, C. Tani, M. Aringer et al., "European league against rheumatism recommendations for monitoring patients with systemic lupus erythematosus in clinical practice and in 
observational studies," Annals of the Rheumatic Diseases, vol. 69, no. 7, pp. 1269-1274, 2010.

[41] K. M. Kunisaki and E. N. Janoff, "Influenza in immunosuppressed populations: a review of infection frequency, morbidity, mortality, and vaccine responses," The Lancet Infectious Diseases, vol. 9, no. 8, pp. 493-504, 2009.

[42] I. Ferreira and D. Isenberg, "Vaccines and biologics," Annals of the Rheumatic Diseases, vol. 73, no. 8, pp. 1446-1454, 2014.

[43] B. Holvast, A. Huckriede, C. G. M. Kallenberg, and M. Bijl, "Influenza vaccination in systemic lupus erythematosus: safe and protective?" Autoimmunity Reviews, vol. 6, no. 5, pp. 300305, 2007.

[44] B. Holvast, A. Huckriede, J. Wilschut et al., "Safety and efficacy of influenza vaccination in systemic lupus erythematosus patients with quiescent disease," Annals of the Rheumatic Diseases, vol. 65, no. 7, pp. 913-918, 2006.

[45] M. Keshtkar-Jahromi, H. Argani, M. Rahnavardi et al., "Antibody response to influenza immunization in kidney transplant recipients receiving either azathioprine or mycophenolate: a controlled trial," American Journal of Nephrology, vol. 28, no. 4, pp. 654-660, 2008.

[46] S. Oren, M. Mandelboim, Y. Braun-Moscovici et al., "Vaccination against influenza in patients with rheumatoid arthritis: the effect of rituximab on the humoral response," Annals of the Rheumatic Diseases, vol. 67, no. 7, pp. 937-941, 2008.

[47] C. Hua, T. Barnetche, B. Combe, and J. Morel, "Effect of methotrexate, anti-tumor necrosis factor $\alpha$, and rituximab on the immune response to influenza and pneumococcal vaccines in patients with rheumatoid arthritis: a systematic review and meta-analysis," Arthritis Care and Research, vol. 66, no. 7, pp. 1016-1026, 2014.

[48] I. Fomin, D. Caspi, V. Levy et al., "Vaccination against influenza in rheumatoid arthritis: the effect of disease modifying drugs, including TNF $\alpha$ blockers," Annals of the Rheumatic Diseases, vol. 65, no. 2, pp. 191-194, 2006.

[49] M. C. Kapetanovic, T. Saxne, J.-Å. Nilsson, and P. Geborek, "Influenza vaccination as model for testing immune modulation induced by anti-TNF and methotrexate therapy in rheumatoid arthritis patients," Rheumatology, vol. 46, no. 4, pp. 608-611, 2007.

[50] O. Elkayam, D. Paran, D. Caspi et al., "Immunogenicity and safety of pneumococcal vaccination in patients with rheumatoid arthritis or systemic lupus erythematosus," Clinical Infectious Diseases, vol. 34, no. 2, pp. 147-153, 2002.

[51] G. S. O’Neill and A. D. Isenberg, "Immunizing patients with systemic lupus erythematosus: a review of effectiveness and safety," Lupus, vol. 15, no. 11, pp. 778-783, 2006.

[52] M. C. Kapetanovic, T. Saxne, A. Sjöholm, L. Truedsson, G. Jönsson, and P. Geborek, "Influence of methotrexate, TNF blockers and prednisolone on antibody responses to pneumococcal polysaccharide vaccine in patients with rheumatoid arthritis," Rheumatology, vol. 45, no. 1, pp. 106-111, 2006.

[53] W. W. Chatham, D. J. Wallace, W. Stohl et al., "Effect of belimumab on vaccine antigen antibodies to influenza, pneumococcal, and tetanus vaccines in patients with systemic lupus erythematosus in the BLISS-76 trial," Journal of Rheumatology, vol. 39, no. 8, pp. 1632-1640, 2012.

[54] M. Science, D. Macgregor, S. E. Richardson, S. Mahant, D. Tran, and A. Bitnun, "Central nervous system complications of varicella-zoster virus," Journal of Pediatrics, vol. 165, no. 4, pp. 779-785, 2014.
[55] D. Guris, A. O. Jumaan, L. Mascola et al., "Changing varicella epidemiology in active surveillance sites-United States, 19952005," Journal of Infectious Diseases, vol. 197, supplement 2, pp. S71-S75, 2008.

[56] A. González-Escalada, L. García-García, P. Viguera-Ester et al., "Seroprevalence of antibodies against measles, rubella, mumps, varicella-zoster, and B. Pertussis in young adults of Madrid, Spain," Human Vaccines and Immunotherapeutics, vol. 9, no. 9, pp. 1918-1925, 2013.

[57] S. A. Galea, A. Sweet, P. Beninger et al., "The safety profile of varicella vaccine: a 10 -year review," The Journal of Infectious Diseases, vol. 197, supplement 2, pp. S165-S169, 2008.

[58] I. Kang and S. H. Park, "Infectious complications in SLE after immunosuppressive therapies," Current Opinion in Rheumatology, vol. 15, no. 5, pp. 528-534, 2003.

[59] M. N. Oxman, M. J. Levin, G. R. Johnson et al., "A vaccine to prevent herpes zoster and postherpetic neuralgia in older adults," The New England Journal of Medicine, vol. 352, no. 22, pp. 2271-2284, 2005.

[60] D. Gilden, "Efficacy of live zoster vaccine in preventing zoster and postherpetic neuralgia," Journal of Internal Medicine, vol. 269, no. 5, pp. 496-506, 2011.

[61] K. E. Schmader, M. J. Levin, J. W. Gnann et al., "Efficacy, safety, and tolerability of herpes zoster vaccine in persons aged 50-59 years," Clinical Infectious Diseases, vol. 54, no. 7, pp. 922-928, 2012.

[62] https://www.clinicaltrials.gov/ct2/show/NCT00546819?term= zostavax+corticosteroid\&rank $=1$.

[63] H. Barte, T. H. Horvath, and G. W. Rutherford, "Yellow fever vaccine for patients with HIV infection," Cochrane Database of Systematic Reviews, no. 1, Article ID CD010929, 2014.

[64] L. S. Azevedo, E. Lasmar, F. Contieri et al., "Yellow fever vaccination in organ transplanted patients: is it safe? A multicenter study," Transplant Infectious Disease, vol. 14, no. 3, pp. 237-241, 2012.

[65] M. A. Hernán, S. S. Jick, M. J. Olek, and H. Jick, "Recombinant hepatitis $B$ vaccine and the risk of multiple sclerosis: a prospective study," Neurology, vol. 63, no. 5, pp. 838-842, 2004.

[66] T. Verstraeten, C. Cohet, G. Dos Santos et al., "Pandemrix ${ }^{\mathrm{TM}}$ and narcolepsy: a critical appraisal of the observational studies," Human Vaccines \& Immunotherapeutics, vol. 12, no. 1, pp. 187193, 2016.

[67] V. Bruzzese, A. Zullo, and C. Hassan, "Connective tissue disease following hepatitis B vaccination," Journal of Clinical Rheumatology, vol. 19, no. 5, pp. 280-281, 2013.

[68] C. Perricone and Y. Shoenfeld, "Hepatitis B vaccination and undifferentiated connective tissue disease: another brick in the wall of the autoimmune/inflammatory syndrome induced by adjuvants (Asia)," Journal of Clinical Rheumatology, vol. 19, no. 5, pp. 231-233, 2013.

[69] M. Gatto, N. Agmon-Levin, A. Soriano et al., "Human papillomavirus vaccine and systemic lupus erythematosus," Clinical Rheumatology, vol. 32, no. 9, pp. 1301-1307, 2013.

[70] V. Martínez-Sernández and A. Figueiras, "Central nervous system demyelinating diseases and recombinant hepatitis B vaccination: a critical systematic review of scientific production," Journal of Neurology, vol. 260, no. 8, pp. 1951-1959, 2013.

[71] A. Hviid, "Postlicensure epidemiology of childhood vaccination: the Danish experience," Expert Review of Vaccines, vol. 5, no. 5, pp. 641-649, 2006. 
[72] J. S. Gerber and P. A. Offit, "Vaccines and autism: a tale of shifting hypotheses," Clinical Infectious Diseases, vol. 48, no. 4 , pp. 456-461, 2009.

[73] M. M. McNeil, J. Gee, E. S. Weintraub et al., "The vaccine safety datalink: successes and challenges monitoring vaccine safety," Vaccine, vol. 32, no. 42, pp. 5390-5398, 2014.

[74] http://www.arscentro.min-saude.pt/SaudePublica/Material/ Documents/5\%20-\%20\%20FICHAS\%20PRODUTO\%20E\% 20SEGURAN\%C3\%87A\%20-\%202007.pdf.

[75] http://www.ema.europa.eu/docs/pt_PT/document_library/ EPAR_-_Summary_for_the_public/human/001104/WC500057248 .pdf. 


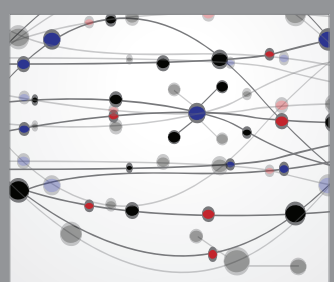

The Scientific World Journal
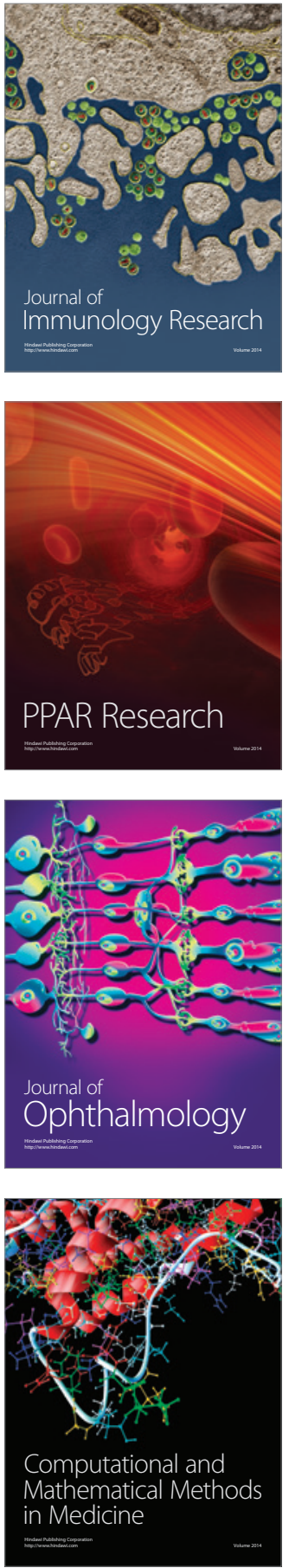

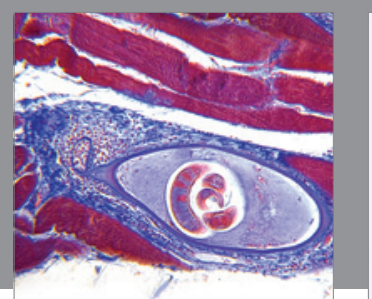

Gastroenterology Research and Practice

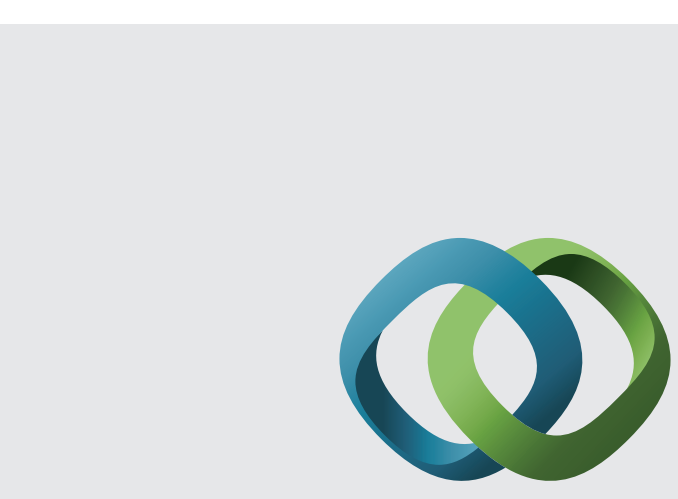

\section{Hindawi}

Submit your manuscripts at

http://www.hindawi.com
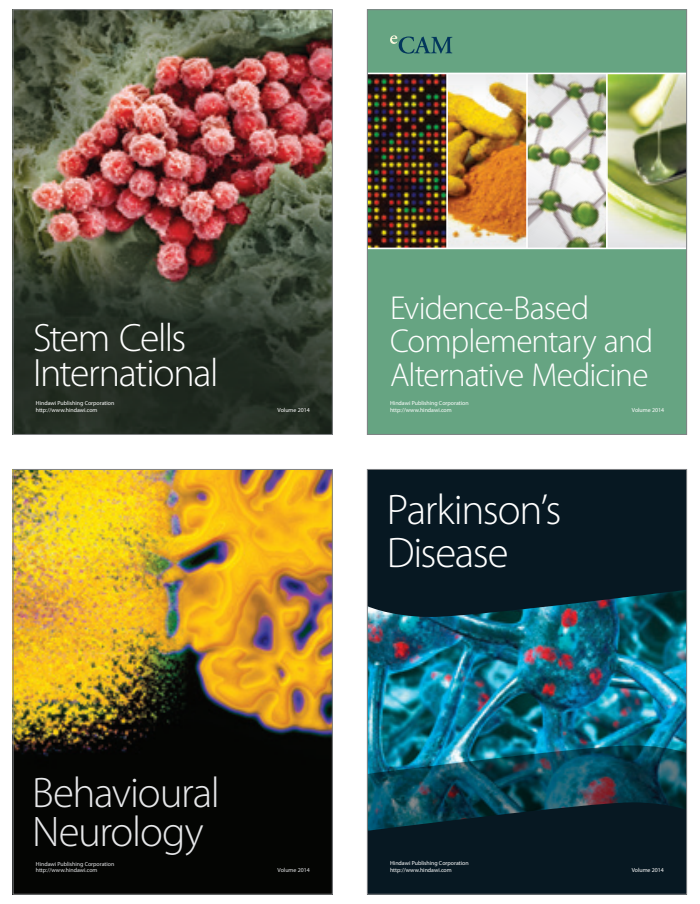
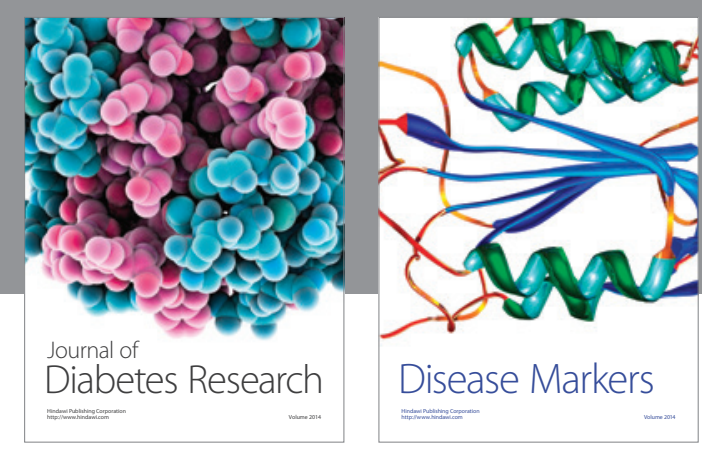

Disease Markers
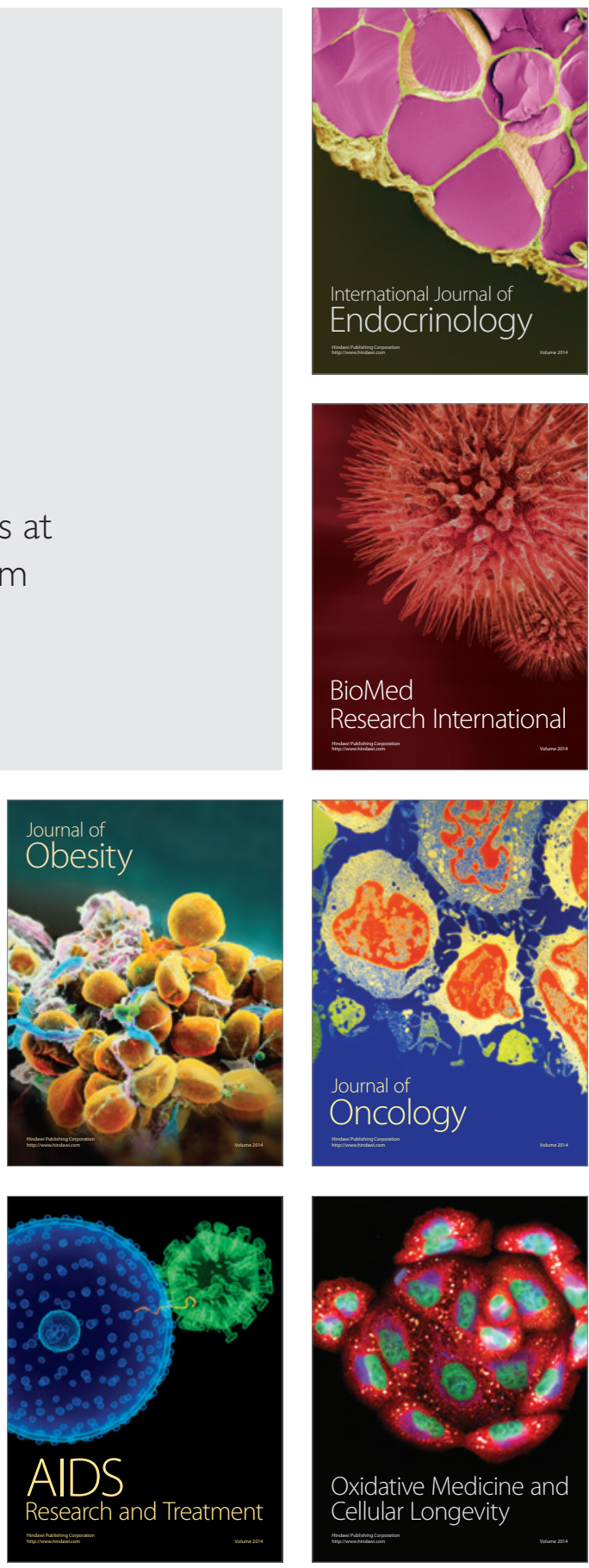